\title{
The Fracture Behaviour of Dental Enamel
}

\author{
Sabine Bechtle ${ }^{1}$, Stefan Habelitz ${ }^{2}$, Arndt Klocke ${ }^{3}$, Theo Fett ${ }^{4}$, Gerold A. Schneider ${ }^{{ }^{*}}$ \\ ${ }^{I}$ Institute of Advanced Ceramics, Hamburg University of Technology, Denickestr. 15, D-21073 \\ Hamburg, Germany \\ ${ }^{2}$ Department of Orofacial Sciences, University of California, \\ San Francisco, CA 94143, USA \\ ${ }^{3}$ Department of Preventive and Restorative Dental Sciences, University of California, \\ San Francisco, CA 94143, USA \\ ${ }^{4}$ Institute for Ceramics in Mechanical Engineering, University of Karlsruhe (TH), Haid und Neu \\ Straße 7, D-76131 Karlsruhe, Germany
}

\begin{abstract}
Enamel is the hardest tissue in the human body covering the crowns of teeth. Whereas the underlying dental material dentin is very well characterised in terms of mechanical and fracture properties, available data for enamel are quite limited and are apart from the most recent investigation mainly based on indentation studies. Within the current study, stable crack-growth experiments in bovine enamel have been performed, to measure fracture resistance curves for enamel. Single edge notched bending specimens (SENB) prepared out of bovine incisors were tested in 3-point bending and subsequently analysed using optical and environmental scanning electron microscopy. Cracks propagated primarily within the proteinrich rod sheaths and crack propagation occurred under an inclined angle to initial notch direction not only due to enamel rod and hydroxyapatite crystallite orientation but potentially also due to protein shearing. Determined mode I fracture resistance curves ranged from $0,8-$ $1,5 \mathrm{MPa}^{*} \mathrm{~m}^{1 / 2}$ at the beginning of crack propagation up to $4,4 \mathrm{MPa}^{*} \mathrm{~m}^{1 / 2}$ at $500 \mu \mathrm{m}$ crack extension; corresponding mode II values ranged from 0,3 to $1,5 \mathrm{MPa}^{*} \mathrm{~m}^{1 / 2}$.
\end{abstract}

Key words: enamel, mechanical properties, fracture behaviour, resistance curves, toughening

\section{Introduction}

Dental enamel (the outer hard tissue layer of tooth crowns) is a composite material that comparable to other biological tissues like bone or dentin - exhibits a unique and complex hierarchical structure. It is composed of $\sim 85 \mathrm{vol} \%$ hydroxyapatite crystals, $\sim 12 \mathrm{vol} \%$ water and $\sim 3 \mathrm{vol} \%$ organic matrix [1]. On the microstructural level enamel is composed of crystal rods (about $5 \mu \mathrm{m}$ in diameter) that run from the dentin-enamel-junction (DEJ) to approximately 6-12 $\mu \mathrm{m}$ below the tooth surface [2]. Each single enamel rod consists of bundles of hydroxyapatite (HAP) crystallites of about $50 \mathrm{~nm}$ in diameter covered by an approximately $1 \mathrm{~nm}$ thick organic layer $[3,4]$.

\footnotetext{
*corresponding author: Gerold A. Schneider (g.schneider@tuhh.de) doi:10.1016/j.biomaterials.2009.09.050
} 
The crystallites are at least $100 \mu \mathrm{m}$ long [5] and some researchers assume that they span over the entire thickness of the enamel layer [6]. The interrod region is formed by HAP crystallites which are arranged parallel to each other but with certain inclinations to adjacent enamel rod axes [2] forming a continuous fibrous matrix that is intercepted by enamel rods. Within the interface between rods and interrod region water and proteins are assumed to accumulate due to lower HAP density in that area [7]. Thus, rod boundaries in enamel appear as distinct protein-rich structures called 'rod sheaths'.

Enamel most often is characterised as a 'brittle' material in comparison to the underlying dentin layer [8] - though the available data for enamel is quite limited if compared to dentin: fracture toughness resistance curves for dentin were published derived from CT- and SENBsamples tested [9 - 12], the effects of sample orientation [13], aging [9], temperature [14] and hydration $[10,11]$ on fracture toughness were investigated as well as observed toughening mechanisms were judged due to their relevance [12]. In contrast, most published fracture toughness values for human enamel are based on indentation studies [8,15 - 18]. The indentation fracture toughness values range from 0,7 to $1,5 \mathrm{MPa}^{*} \mathrm{~m}^{1 / 2}$ and are based on Vickers microindentation methods. The values vary slightly due to location of indentation with respect to distance from the DEJ [8] and depending on enamel rod orientation [15,17], and enamel is found to be three times tougher than its main constituent HAP [15]. However, toughness values rely on the semi-empirical equation

$K_{C}=\chi\left(\frac{E}{H}\right)^{1 / 2} \cdot \frac{P}{a^{3 / 2}}$

where $\mathrm{K}_{\mathrm{c}}$ is the fracture toughness, $\mathrm{E}$ the Young's modulus and $\mathrm{H}$ the hardness of the material, $\mathrm{a}$ is the crack length, $\mathrm{P}$ the indentation load, and $\chi$ is an empirically calibrated constant $[19,20]$. This empirical constant leads to an inherent uncertainty in the deduced indentation toughness values. A major advantage of the Vickers indentation method is the easy experimental set-up but the drawback are uncertainties concerning crack morphology and residual stress field. Lately, it was even concluded that 'the Vickers indentation fracture toughness test is not reliable at all' and 'should not be applied for any fracture resistance measurements of ceramics or other brittle materials' [21].

Quite recently, a detailed study of fracture toughness resistance curves for human enamel was published [22] based on fracture mechanical testing and evaluation of compact tension (CT) specimens consisting of human enamel cubes mounted in epoxy resin. Determined fracture toughness values ranged from $0,5-0,8 \mathrm{MPa}^{*} \mathrm{~m}^{1 / 2}$ at the beginning of crack propagation up to $2,4 \mathrm{MPa}^{*} \mathrm{~m}^{1 / 2}$ at $1,5 \mathrm{~mm}$ crack extension, being in good agreement with the previously published indentation toughness values, though being slightly higher after some crack propagation. A distinct difference between regions close to the DEJ and enamel outer surface regions in terms of fracture behaviour was observed. Crack deflection, crack bridging and microcracking were detected to increase fracture toughness with crack extension.

However - considering the limited amount of published data concerning the mechanical and fracture behaviour of enamel - one has to conclude that the dental material enamel is far from being well defined in terms of these properties if compared to dentin or other biomaterials like bone. This might be due to the constraints in material availability and the accompanying difficulties of sample preparation for mechanical testing. For this reason, bovine instead of human enamel was used in this study: due to the larger size of bovine teeth and the thicker enamel layer, the extraction of bending bars was possible. Hence, edge notched bending 
specimens (SENB) were tested in 3-point bending and fracture resistance curves for enamel were calculated. Crack profiles and fracture surfaces were further analysed using optical and scanning electron microscopy to link the obtained fracture parameters with enamel microstructure.

\section{Material and Methods}

\subsection{Methods}

Fracture resistance curves were determined using a custom-made three-point bending device equipped with a quartz load sensor (quartz dynamic load cell 9212, Kistler Instrumente $\mathrm{GmbH})$ of high sensitivity $(-11,3 \mathrm{pC} / \mathrm{N})$ to measure the force acting on the sample and an optical microscope with 400x magnification for visual crack length determination. The load within the loading range applied $(0-10 \mathrm{~N})$ was measured with $5 \%$ accuracy; the crack length was determined accurate to $3 \mu \mathrm{m}$.

A 3-point bending cell with a loading span $\mathrm{S}$ of $7 \mathrm{~mm}$ was used. The lower support was fixed whereas the displacement of the upper support (and thus the load acting on the sample) could be changed manually. For a more detailed description of the bending device used see [23].

Sets of measuring points $\left(\mathrm{P}_{\mathrm{i}}, \mathrm{a}_{\mathrm{i}}\right)$ were determined by carefully loading a previously notched enamel bending bar with $P_{i}$ being the force at the beginning of crack propagation and $a_{i}$ being the corresponding crack length. Samples were repeatedly loaded and unloaded to control crack propagation and to monitor as many sets of measuring points as possible for each sample.

As crack propagation occurred under a constant inclined angle to the initial notch direction, mixed-mode stress conditions were introduced at the crack tip - more precisely a combination of mode I (tensile) and mode II (in-plane shear) stresses. Using the determined sets of measuring points $\left(\mathrm{P}_{\mathrm{i}}, \mathrm{a}_{\mathrm{i}}\right)$, mode I and mode II stress intensities $\mathrm{K}_{\mathrm{I}}, \mathrm{K}_{\mathrm{II}}$ acting simultaneously at the crack tip during crack propagation were calculated using the geometric functions $F_{I}$ and $F_{\text {II }}$ for oblique crack propagation in 3-point bending (detailed formulas for $F_{I}$ and $F_{I I}$ see appendix):

$$
K_{I, I I}=\sigma \sqrt{\pi a_{i}} \cdot F_{I, I I}\left(a_{i}\right) \quad \text { and } \quad \sigma=\frac{3 S P_{i}}{2 t W^{2}}
$$

where $\mathrm{S}$ is the loading span, $\mathrm{t}$ the sample thickness, and $\mathrm{W}$ the sample width.

The precision of the bending device was verified using well-known ferroelectric PZT ceramic samples (PIC 151) [23]. Crack propagation in these samples occurred without inclination to initial notch direction and calculated fracture toughness values using standard handbook linear-elastic mode I solution for SENB geometry [24] were in good agreement with published data $[23,25]$. In addition, bovine dentin samples were measured as well. Crack growth resistance curves as published in [9] that were derived from human dentin samples tested in 3-point bending could be reproduced for bovine dentin.

After mechanical testing, crack profiles and fracture surfaces were analysed using a common optical microscope and an environmental scanning electron microscope (ESEM) (Hitachi 
BIOMATERIALS 31 (2010) 375-384

America, Pleasanton, CA). With the latter, images were made at $15-20 \mathrm{kV}$ using backscattering mode at a pressure of $100 \mathrm{~Pa}$ and a temperature of $25^{\circ} \mathrm{C}$.

\subsection{Material}

Bovine permanent mandibular incisors $(n=9)$ were used for the current study due to their larger amount of enamel available compared to human teeth. It has been previously pointed out that bovine enamel exhibits a very similar microstructure to human enamel with same enamel rod size and shape, and same amounts of constituents (HAP and organic components) [26,27]. Rectangular shaped bending bars $\left(\sim 1 \times 1 \times 10 \mathrm{~mm}^{3}\right)$ consisting purely of enamel were prepared. Final polishing of all bending bar surfaces was done using 600 grit SiC paper. The samples were subsequently notched to roughly 30 - $40 \%$ of their total width using a razor blade irrigated with $10 \mu \mathrm{m}$ diamond suspension, and the notch was then sharpened to a radius of $\sim 20 \mu \mathrm{m}$ using a razor blade irrigated with $1 \mu \mathrm{m}$ diamond suspension. Notches were placed in two different orientations with respect to the expected enamel rod orientation, see Figure 1. In the 'transversal orientation' (5 samples) enamel rods run from the front to the back sample side with an inclination downwards $\left(\sim 22^{\circ}\right)$ and sidewards $\left(\sim 45^{\circ}\right)$. In the 'longitudinal orientation' (4 samples) enamel rods run from the bottom up with an inclination backwards ( $\left.22^{\circ}\right)$ and sidewards $\left(\sim 45^{\circ}\right)$.

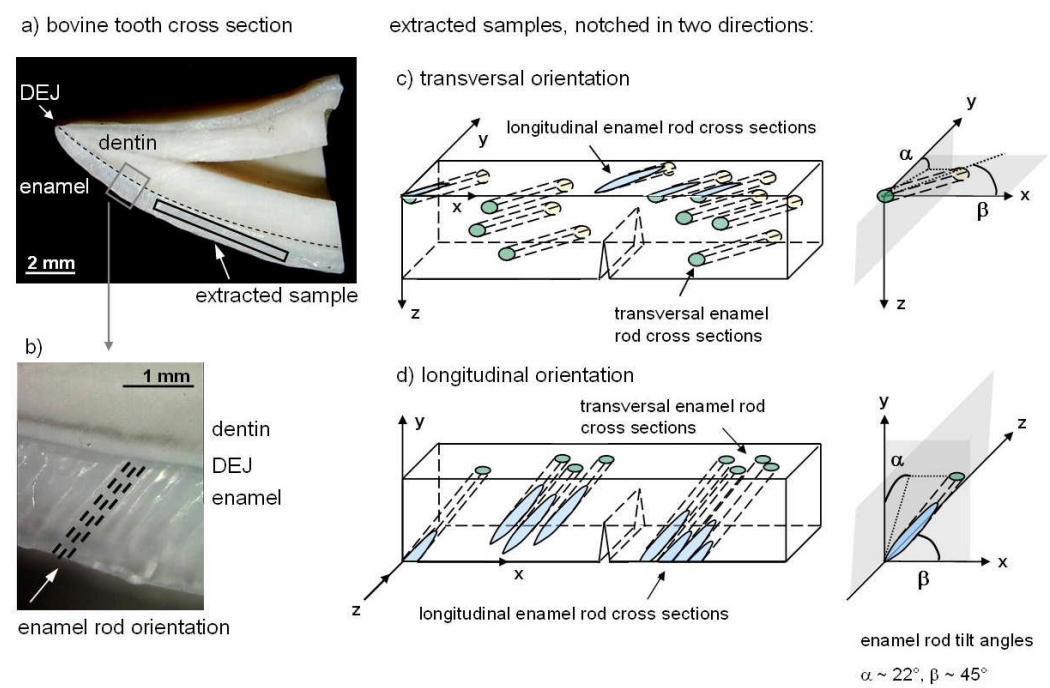

Figure 1: Bovine tooth cross section with location of extracted sample and sample orientation. a) Bovine tooth cross section. b) Enlarged image of enamel layer with expected enamel rod orientation indicated. c) Notched sample in transversal orientation: enamel rods run from the front to the back side with an inclination downwards $\left(\alpha \sim 22^{\circ}\right)$ and sidewards $\left(\beta \sim 45^{\circ}\right)$. d) Notched sample in longitudinal orientation: enamel rods run from bottom up with an inclination backwards $\left(\alpha \sim 22^{\circ}\right)$ and sidewards $(\beta$ $\sim 45^{\circ}$ ). 
The bending bar front side, on which crack propagation was visually monitored, was further polished using $1 \mu \mathrm{m}$ and $0,25 \mu \mathrm{m}$ diamond suspension. Samples were additionally gold coated with a $5 \mathrm{~nm}$ gold layer prior to mechanical testing to improve the visibility of the propagating cracks. For ESEM images, tested samples were additionally polished with 0,05 $\mu \mathrm{m}$ diamond and colloidal silica polishing suspension (Mastermet 2, Buehler Germany) to make the enamel microstructure visible.

Samples were stored in Hanks' Balanced Salt Solution (HBSS, Invitrogen, USA) at all times in order to minimize surface demineralization and, subsequently, changes in mechanical properties [28]. During preparation steps, samples were always irrigated with fluid. After preparation was completed, samples were stored at least 12 - 24h in HBBS before mechanical testing. Samples were then removed from the solution and wiped. Mechanical testing in ambient air was completed within 30 minutes after removing the samples from the HBSS environment.

\section{Results}

Typical optical microscope crack path images are shown in Figures 2a and 3a. All cracks grew with an oblique angle of approximately $45^{\circ}$ from initial notch direction independent of sample orientation with the crack plane always being perpendicular to the surface. Details of the enamel microstructure and the crack profile can be seen in the ESEM images in figures $2 b$ $\& \mathrm{c}$ and $3 \mathrm{~b} \& \mathrm{c}$. In the transversal orientation (Figure 2), the enamel rod cross sections appear slightly elliptically shaped all-over the sample surface. There is one main crack propagating, accompanied by short cracks that arise through crack branching and join the main crack again on $\mu \mathrm{m}$-lengths scales (labelled as 'meandering cracks'). In some areas, crack branches leave the main crack at an angle of $90^{\circ}$ (Figure 2c), extending about 20-50 $\mu \mathrm{m}$. Approximately 85\% of the crack path of main and side cracks lie within the protein-rich rod sheaths, only some rods are cracked (as shown in Figure 2b). In the ESEM images of the longitudinal orientation (Figures $3 b \quad \& \quad c$ ), enamel rod orientation appears not as uniform as for the transversal orientation: in the lower sample part around the notch, the enamel rods are roughly perpendicular to the surface and appear as ellipses. They are aligned in closely packed rows that are separated by relatively wide interrod regions as indicated in Figure 3b. Above the notch, these rows start to tilt until they run completely parallel to the surface in the upper part of the sample being inclined about $45^{\circ}$ to the notch direction. Crack propagation occured within the protein-rich rod sheaths and in the beginning, the crack propagated almost in notch direction. Arriving at the region where enamel rod orientation changes, the crack also started to tilt after about $60 \mu \mathrm{m}$ of propagation and then ran very straight and parallel to the rods. Within the transition region where rod and crack tilting begins, uncracked ligament bridging occured. 

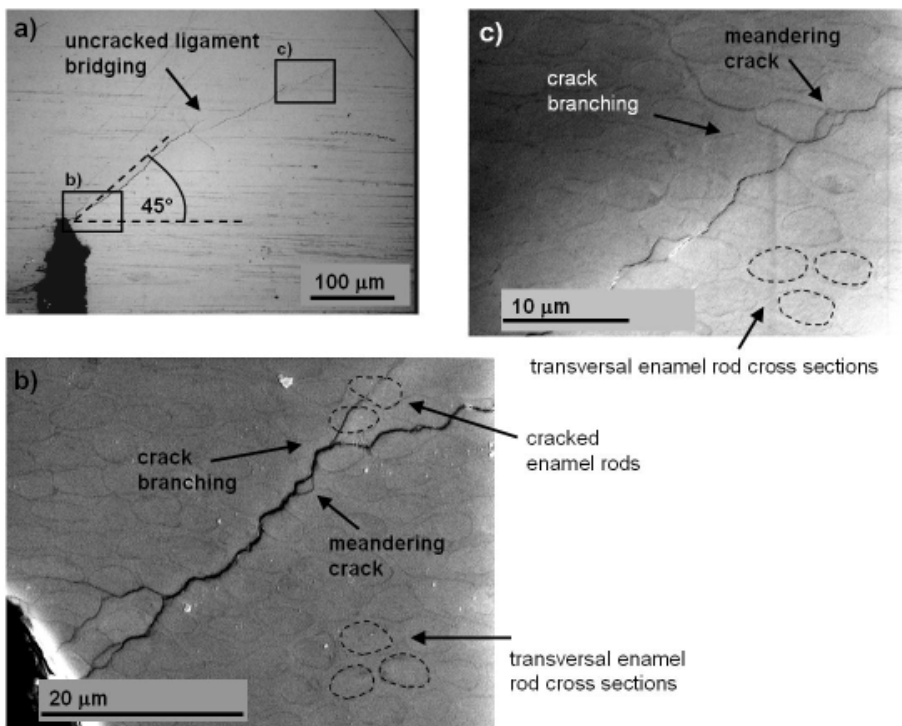

Figure 2: Crack path in a transversal orientated sample. Cracks propagated at about $45^{\circ}$ to initial notch direction exhibiting crack branching as major visible toughening mechanism. The labelled 'meandering cracks' are branches that join the main crack again after some micrometer propagation. Additionally, uncracked ligament bridging could be observed. Cross sections of enamel rods are visible in the ESEM images ( $b$ \& c) and appear as ellipses. As these images show, crack propagation mainly occurred within the proteinrich rod sheaths.
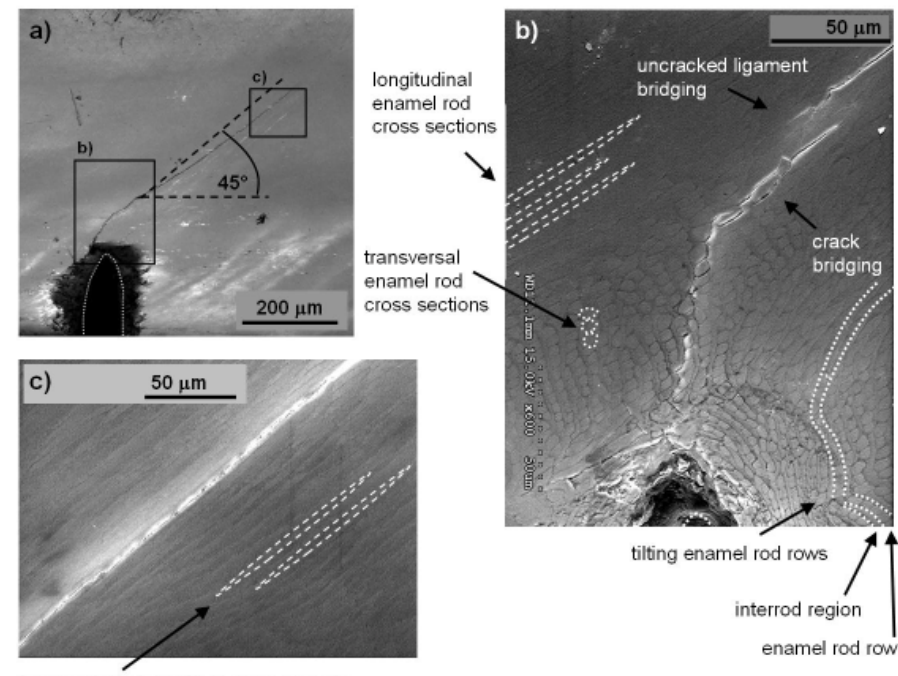

longitudinal enamel rod cross sections

Figure 3: Crack path in a longitudinally orientated sample.

Enamel rods are roughly perpendicular to the surface in the lower part of the sample and parallel to the surface in the upper part. Crack propagation occurred within the protein-rich rod sheaths and the crack path followed the inclined direction provided by enamel rods. Uncracked ligament bridging occurred within the transition region where rod orientation and crack direction changed. 
Figures 4 and 5 show the fracture surfaces of a transversal and a longitudinal sample. In the transversal sample (Figure 4), the single enamel rods are very well visible and three different fracture areas can be distinguished. They are marked with ' $A$ ', 'B', 'C' and enlarged images of these regions are displayed. In the longitudinal sample (Figure 5), two regions can be distinguished - the one close to the notch with a wavy rod arrangement ('A') and the upper part of the sample ('B') where enamel rods run very straight and parallel to the sample surface.

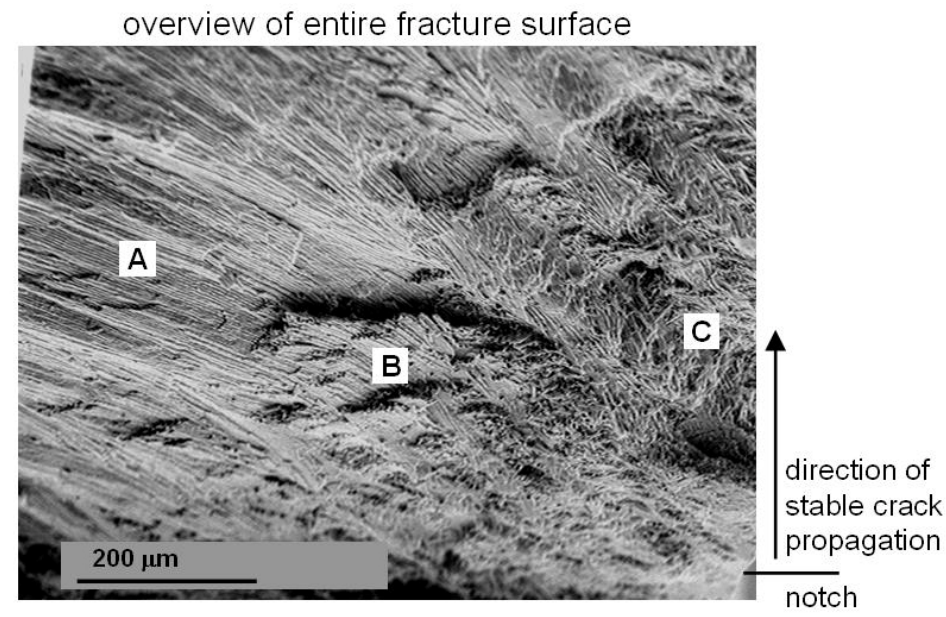

enlarged images of regions $A, B, C$
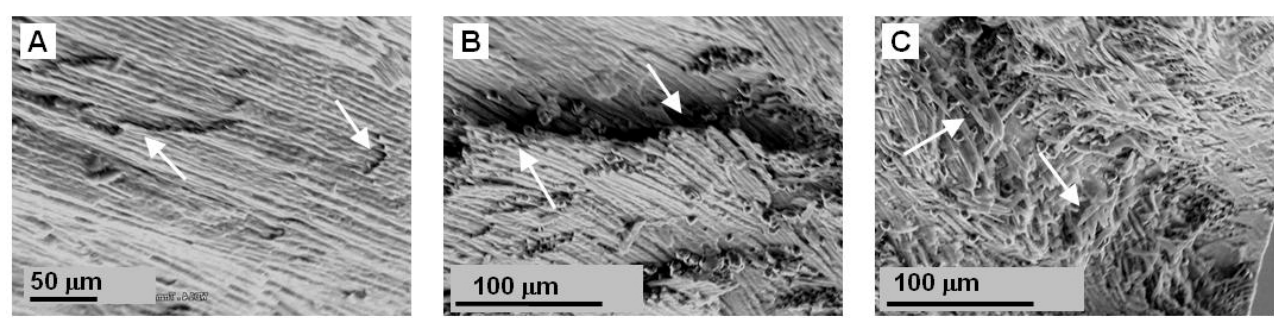

Figure 4: Fracture surface of a transversal enamel sample: Single enamel rods can be recognized easily. Three differing fracture areas can be distinguished - noted with 'A', ' $\mathrm{B}$ ', and ' $\mathrm{C}$ '. Enamel rods are very straight and parallel to the fracture surface with an inclination downwards of about $22^{\circ}$ in area 'A'. Fracture in this region occurred completely parallel to enamel rod long axes. In region ' $\mathrm{B}$ ', layers of enamel rods are fractured. In region ' $\mathrm{C}$ ', several rods are fractured and enamel rod long axes are inclined to the fracture surface. Arrows indicate single broken rods (A), broken rod layers (B), and several broken rods $(\mathrm{C})$. 

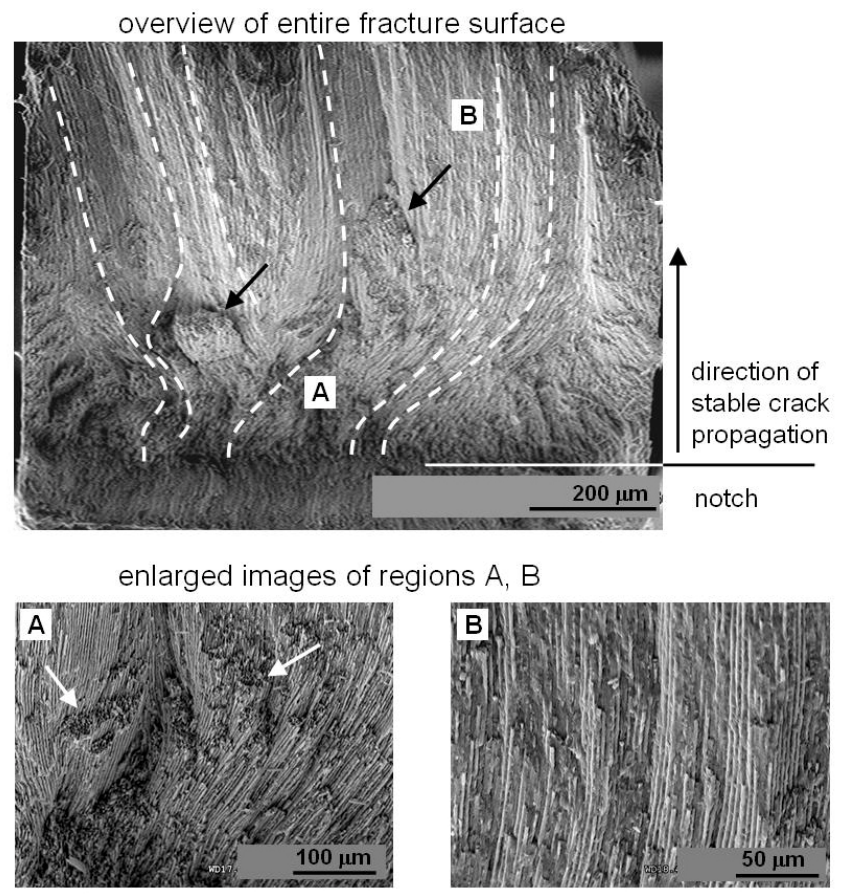

Figure 5: Fracture surface of a longitudinal enamel sample: In the area close to the notch ('A') enamel rods are parallel to each other but tend to form wavy lines whereas in the upper part of the sample ('B') the rods are very straight and parallel as visualised by dashed lines. Arrows indicate broken rod bundles.

Figure 6 displays the determined mode I and mode II fracture resistance curves of enamel for both orientations tested. The corresponding $K_{I}$ - and $K_{I I}$ - values both increase with increasing crack length. For simplicity and because of the lack of a known fracture criterion for enamel under mixed mode loading we denote these values as $K_{I R}^{*}$ and $K_{I I R}^{*}$. The ' $\mathrm{R}$ ' indicates that this is the corresponding $K_{I}$ and $K_{I I}$ during stable crack growth. The '*', indicates that this is not a fracture resistance in the usual sense, because we do not know how it would change under different $K_{I}, K_{I I}$ combinations. For the transversal samples, $K_{I R}^{*}$ lies between 1,0 and 1,5 $\mathrm{MPa}^{*} \mathrm{~m}^{1 / 2}$ at the beginning of crack propagation and rises up to $4-4,4$ $\mathrm{MPa}^{*} \mathrm{~m}^{1 / 2}$ at a crack extension of $500 \mu \mathrm{m}$. For the longitudinal samples, $K_{I R}^{*}$ values lie between 0,8 and $1,4 \mathrm{MPa}^{*} \mathrm{~m}^{1 / 2}$ at the beginning of crack propagation and rise up to 2,6 $\mathrm{MPa}^{*} \mathrm{~m}^{1 / 2}$ at $200 \mu \mathrm{m}$ crack extension. Apart from the values for $\Delta \mathrm{a}=0 \mu \mathrm{m}$, the $K_{I R}^{*}$ values for the longitudinal samples show a smaller amount of scattering than values of the transversal samples and lie within the upper $K_{I R}^{*}$ - range of the corresponding values determined for the transversal samples.

$K_{I I R}^{*}$ - values are always about one fourth to one third of the $K_{I R}^{*}$ values for both tested orientations at all crack lengths and therefore, observed trends for $K_{I R}^{*}$ are also valid for $K_{I R}^{*}$. This is visualized in Figure 7 , where the $K_{I R}^{*} / K_{I I R}^{*}$ - ratio is plotted as a function of crack extension $\Delta \mathrm{a}$. 
BIOMATERIALS 31 (2010) 375-384

a) transversal orientation

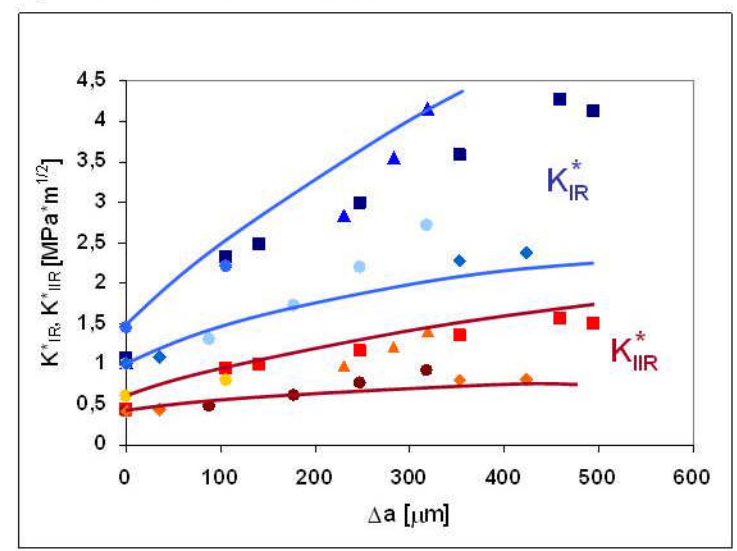

b) longitudinal orientation

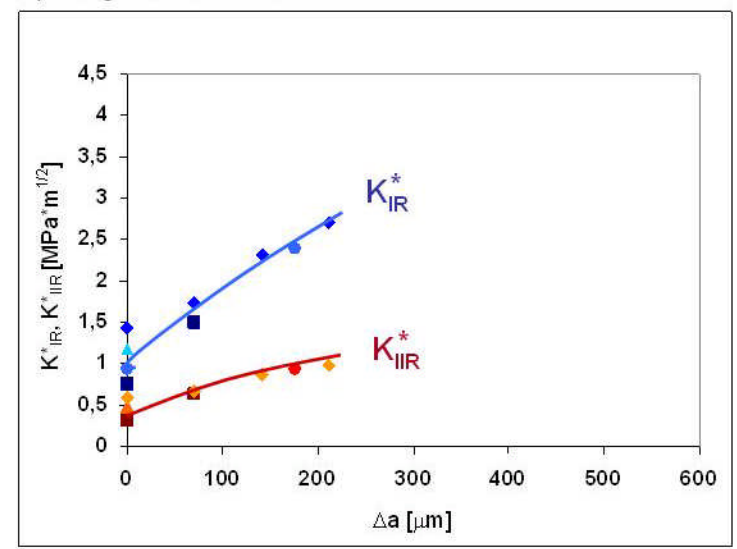

Figure 6: Fracture resistance curves for enamel in a) the transversal and b) the longitudinal orientation: The mode I $\left(K_{I R}^{*}-\right.$ coloured in blue tones) and mode II ( $K_{I I R}^{*}$ - coloured in red tones) values are plotted as a function of crack extension $\Delta$ a. Each data point type represents a separate sample. For definition of $K_{I R}^{*}$ and $K_{I I R}^{*}$ see text. 


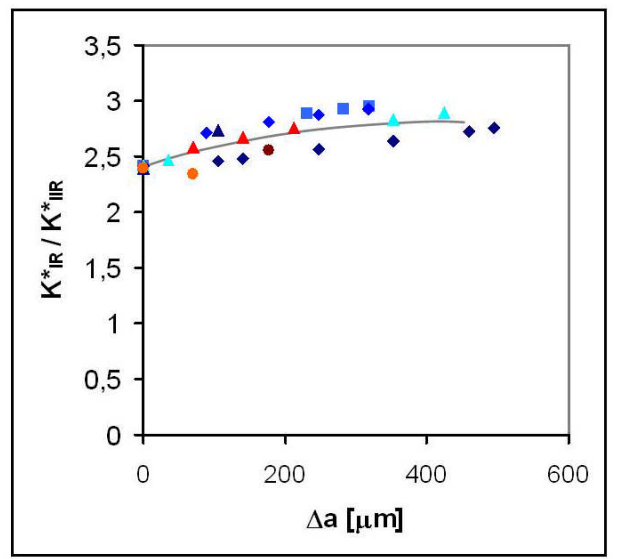

Figure 7: $K_{I R}^{*} / K_{I I R}^{*}$-ratio. Both sample groups are included (transversal: blue tones, longitudinal: red tones). The ratio increases slightly with increasing crack length.

\section{Discussion}

In this study we present the first fracture resistance curves for enamel derived from fracture mechanical testing and evaluation of SENB samples and show that enamel exhibits rising fracture resistance behaviour. Macroscopically, shear fracture occurred [29] with fracture surfaces at $45^{\circ}$ to acting tensile stresses independent of sample orientation. On the microstructural level, one could observe that stable crack propagation predominantly occurred within the protein-rich sheaths that envelop enamel rods and separate them from adjacent rods and interrod regions. In the longitudinal orientation, the oblique orientation of enamel rods apparently forced cracks on their oblique paths. This indicates that it was more favourable for cracks to propagate within the protein-rich phase than to cross enamel rods and break HAP crystals apart. However, in the transversal orientation, oblique crack propagation was not caused by enamel rod orientation. The cracks could as well propagate straight ahead from the notch by meandering around single rods like intergranular crack propagation commonly occurs in ceramic materials. The question arises why even so in this case, shear fracture happened. In our opinion there are two reasons that might have promoted shearing in the transversal samples: HAP crystallite orientation within the interrod region or shearing of proteins forming the rod sheaths. Inside the interrod region the orientation of HAP crystallites differs substantially from their orientation within the rods. Thus, the local tilted direction of HAP crystallites within this area might have forced cracks on their oblique paths. Furthermore we assume that water and proteins accumulate within the interface between rods and interrod region as already proposed by other researchers [7]. Consequently, this interface is mechanically weaker than rods and interrod region and fracture along this interface is most probable. This indeed could be observed in this study (see ESEM images in figures 2 and 3). Thus, it is possible that fracture occurred by shearing deformation of this weak interface: crack propagation probably was promoted by proteins that were stretched under shear up to a 
BIOMATERIALS 31 (2010) 375-384

critical length and broke. It seems likely that this was the fracture mechanism in the longitudinal samples also, but in these samples the rod structure was an additional factor enforcing oblique crack propagation.

Two main mechanisms could be observed leading to a rising fracture resistance curve: crack branching (including the as-labelled 'meandering cracks') and uncracked ligament bridging. In the transversal orientation, both mechanisms could be observed, distributed over the entire crack length. In the longitudinal samples, only crack bridging occurred - predominantly at the beginning of crack formation (see Figures $3 \mathrm{~b}$ and 5; in the latter one the indicated broken rod bundles might have acted as bridges before fracture). However, most of the crack profile in Figure 3 and of the fracture surface in Figure 5 shows very straight crack paths parallel to the enamel rods without any branches or bridges. Since the determined $K_{I R}^{*}$ and $K_{I I R}^{*}$ values rise continually, we assume that either the uncracked ligaments had to effectively bridge the crack until samples fractured and, thus, being accountable for the entire increase of fracture resistance or additional toughening mechanisms were acting during crack propagation, for example protein bridging as observed by other researchers in both enamel [22] and dentin [12].

The uncracked ligaments in the longitudinal samples were formed in sample areas where enamel rods were orientated wavy and inclined instead of straight and parallel as expected (note discrepancy between expected straight rod orientation in Figure 1 and wavy, nonuniform rod arrangement displayed in micrographs in Figures 3 and 5). It seems that the partially wavy arrangement in principle enabled ligament formation and, thus, possibly the wavy rod arrangement is the key feature generating crack resistance of enamel in lifetime (cracks in complete teeth tend to propagate perpendicular to the DEJ parallel to enamel rods $[30,31]$ and hence can be compared with cracks in the longitudinal tested samples).

Figure 8 again displays the simplified enamel model that was already used in section 2 ('Materials and Methods') to visualize the notch orientation with respect to expected enamel rod orientation. This time, the fracture planes are inserted as well. Comparing the model fracture planes with the fracture surfaces in Figures 4 and 5 it becomes obvious that the longitudinal samples can fracture at $45^{\circ}$ to the notch completely parallel to enamel rod long axes without the necessity to fracture any rods. In the transversal samples, it can be observed as well that fracture planes were always perpendicular to the sample front side and did hardly tilt in the interior of the samples. Thus, enamel rods had to be fractured to maintain the observed non-tilted fracture planes in this orientation although the 'true' enamel rod orientation slightly differed from the 'model' enamel rod orientation: In region 'A' of the transversal fracture surface (Figure 4), the enamel rod axes roughly lay within the fracture plane - in this region, the angle $\beta$ as indicated in our model, was likely smaller than $45^{\circ}$. In the middle of the sample (region ' $\mathrm{B}$ '), the rods tilted and $\beta$ became larger. Hence, enamel rod layers were fractured. Finally, in region ' $\mathrm{C}$ ' the enamel rods crossed the fracture surface at a steeper angle (comparable to the $45^{\circ}$ angle sidewards used in our model) and thus, several rods had to be fractured. Accordingly - although it was denoted due to the ESEM crack profiles that the preferred crack propagation paths were the protein-rich rod sheaths - enamel rods and thus HAP crystals were broken in the transversal samples in order to maintain straight fracture planes. 


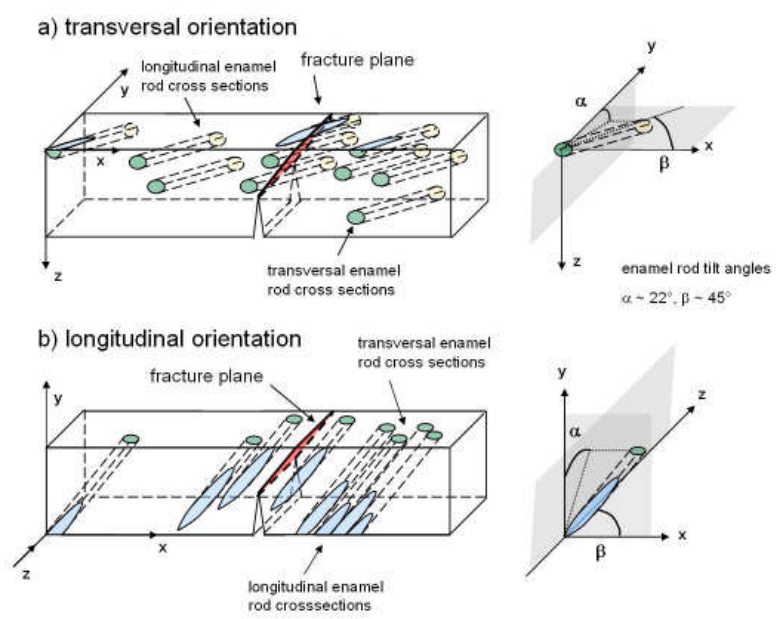

Figure 8: Simplified model of enamel bending bars including notch and fracture plane. In the transversal samples, enamel rods had to be fractured in order to maintain straight fracture planes whereas longitudinal samples could fracture completely parallel to enamel rod long axes.

The obtained mode I $K_{I R}^{*}$ values for enamel range from $0,8-1,5 \mathrm{MPa}^{*} \mathrm{~m}^{1 / 2}$ at the beginning of crack propagation up to $4,4 \mathrm{MPa}^{*} \mathrm{~m}^{1 / 2}$ for $500 \mu \mathrm{m}$ crack extension. At first, these values seem to be much higher than the published fracture toughness $K_{I C}$ values [8,15-18] based on indentation methods ranging from 0,7 to $1,5 \mathrm{MPa}^{*} \mathrm{~m}^{1 / 2}$. However, including the corresponding crack lengths into this comparison (30 to $70 \mu \mathrm{m})$, the difference of the values obtained by the two methods lies within the experimental scatter of the data. Figure 9 shows the relevant section of the $K_{I R}^{*}$ values obtained in this study, including the range of published indentation toughness values $K_{I C}$.

The recently published [22] fracture toughness values derived form CT samples consisting of human enamel cubes mounted in epoxy resin range from $0,5-0,8 \mathrm{MPa}^{*} \mathrm{~m}^{1 / 2}$ at the beginning of crack propagation up to $2,4 \mathrm{MPa}^{*} \mathrm{~m}^{1 / 2}$ at $1,5 \mathrm{~mm}$ crack extension. Fracture toughness was found to be constant within the so-called 'outer enamel' (the enamel layer close to the outer tooth surface). Toughening occurred solely within the 'inner enamel' (the enamel layer close to the DEJ) where enamel rods in human enamel were observed to start to decussate. Crack deflection, crack bridging and microcracking were found to account for the increase in fracture toughness with crack extension. The $K_{I R}^{*}$ values presented in this study are higher than the published mode I fracture toughness values and no plateau of $K_{I R}^{*}$ was observed that could be linked to a specific sample site. Additionally - due to oblique crack propagation $K_{I I R}^{*}$ values were calculated in this study by accounting the induced mixed-mode stress intensities.

The $K_{I R}^{*}$ values obtained in this study range from 0,8 to $1,5 \mathrm{MPa}^{*} \mathrm{~m}^{1 / 2}$ at the beginning of crack propagation. This large scatter might be caused by uncertainties of the initial notch length and by notch radius effects: As can be seen in Figure 3a (the actual notch profile is 
approximated by a dashed line), some enamel particles broke away around the notch on the sample surface - this on the one hand makes a precise measurement of the initial notch length difficult and on the other hand widens the notch radius on the sample surface. Too wide notches result in too large initial $K_{I R}^{*}, K_{I I R}^{*}$ values [24] whereas imprecisely determined initial notch lengths can result in both too large and too small $K_{I R}^{*}, K_{I I R}^{*}$ values. With further crack extension the values for the transversal samples show larger scatter than the values of the longitudinal samples. Furthermore, the longitudinal values lie within the upper range of values determined for the transversal samples. The larger scatter of the transversal samples might be due to toughening mechanisms like crack branching or meandering cracks that occur in a statistically scattered manner with some variations in frequency between samples. These mechanisms were not observed in the longitudinal samples where uncracked ligament bridges were the striking observable toughening mechanism. If these bridges were predominantly accountable for the rising fracture resistance of the longitudinal samples, the smaller scatter might be due to the more uniform distribution of these bridges at the beginning of crack propagation. The larger values of the longitudinal samples again might be explained by the uncracked ligament bridges that possibly were more effective in toughening than the crack branches and meandering cracks in the transversal samples. However, in some transversal samples uncracked ligaments were observed as well as some transversal samples reached the same high values as the longitudinal samples. However, at this point we can only speculate what caused the differences in scatter and magnitude of the determined $K_{I R}^{*}, K_{I I R}^{*}$ values of the two sample groups tested.

Comparing the obtained $K_{I R}^{*}$ values of bovine enamel with fracture toughness $K_{I C}$ values for dentin as published in [9] for human dentin with the values being reproduced by the authors for bovine dentin as noted previously (see section 2.1), one can see that the values for enamel are slightly higher than those received for dentin: $K_{I R}^{*}$ values at the beginning of crack propagation in enamel are about $0,8-1,5 \mathrm{MPa}^{*} \mathrm{~m}^{1 / 2}$, the $K_{I C}$ values for dentin $0,4-1,2$ $\mathrm{MPa}^{*} \mathrm{~m}^{1 / 2}$. At $300 \mu \mathrm{m}$ crack extension, enamel reaches toughness values between 2,2 and 3,5 $\mathrm{MPa}^{*} \mathrm{~m}^{1 / 2}$, dentin values are between 1,5 and $2,5 \mathrm{MPa}^{*} \mathrm{~m}^{1 / 2}$. Thus, enamel seems to be slightly tougher than the underlying dentin. This result is astonishing as the amount of soft, organic material is much larger in dentin $(33 \mathrm{vol} \%)$ than in enamel $(3 \mathrm{vol} \%)$ - a hint, that the hierarchical structure of enamel possibly is more effectively organized to resist crack propagation than the porous dentin structure.

As reported in literature, cracks inserted within enamel pass the enamel layer but tend to arrest as they reach dentin [8,32]. Other researchers [30,33] observed cracks starting at socalled 'tufts' (protein filled hypomineralized fissures) in the vicinity of the DEJ growing away from the DEJ within the enamel layer without penetrating the underlying dentin.

In combination with our findings of enamel being slightly tougher than dentin, this again is astonishing: cracks penetrate the tougher material whereas the less tough one remains intact. Thus we assume that the DEJ has to be tougher than both enamel and dentin as already proposed by other researchers [8,31]. However, as neither the DEJ structure nor its mechanical properties are that well-defined up to now, those aspects have to be focused on in further studies. 


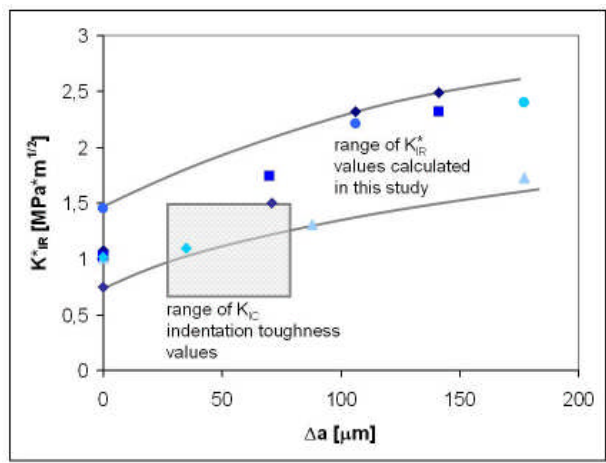

Figure 9: Comparison of published indentation toughness values $[8,15-18]$ and $K_{I R}^{*}$ values derived in this study. Indentation fracture toughness values range from 0,7 to $1,5 \mathrm{MPa}^{*} \mathrm{~m}^{1 / 2}$ and corresponding crack lengths vary between 30 and $70 \mu \mathrm{m}$; the shaded box covers this area. The obtained trends for indentation toughness $K_{I C}$ and determined $K_{I R}^{*} \quad$ values overlap, with indentation values being slightly lower.

\section{Conclusion}

Based on 3-point bending measurements of bovine enamel SENB samples and subsequent microscopic analysis of crack profiles and fracture surfaces, the following conclusions can be drawn:

1. Crack propagation takes place at $45^{\circ}$ to initial notch direction for both longitudinally and transversal orientated enamel rods.

2. The preferred crack propagation path in enamel is the protein-rich interface between enamel rods and interrod region.

3. The macroscopically observed shear fracture at $45^{\circ}$ to initial notch direction can microscopically be explained by oblique enamel rod orientation, protein shearing, and HAP crystallite orientation.

4. Enamel exhibits rising fracture resistance curve behaviour with mode I values ranging from $0,8-1,5 \mathrm{MPa}^{*} \mathrm{~m}^{1 / 2}$ at the beginning of crack propagation up to $4,4 \mathrm{MPa}^{*} \mathrm{~m}^{1 / 2}$ at $500 \mu \mathrm{m}$ crack extension; the corresponding mode II values were found to be one fourth to one third of the mode I values. No significant difference was observed between the fracture resistance behaviour of enamel depending on sample orientation.

5. Enamel was found to be slightly tougher than the underlying dentin - reported crack arresting at the DEJ has to be further investigated in consideration of this finding. 


\section{Acknowledgements}

This manuscript was submitted to the Journal of Biomaterials (Elsevier; http://www.elsevier.com/wps/find/P10_162.cws_home/main) and is available online by 29 September 2009 under doi:10.1016/j.biomaterials.2009.09.050.

Printed version: Bechtle S, Habelitz S, Klocke A, Fett T, Schneider GA. The Fracture Behaviour of Dental Enamel 31: 375-384 (2010).

The authors gratefully thank Dr. Neda Meshkin for specimen preparation and Profs. Sally M. and Grayson W. Marshall of the Department of Preventive and Restorative Dental Sciences, University of California for their scientific support. Financial support for this study was provided by NIH/NIDCR grant RO1:DE017529.

\section{References}

[1] Lussi A. Dental erosion: From diagnosis to therapy. $1^{\text {st }}$ ed. Basel: Karger; 2006.

[2] Gray H, Bannister LH, Berry MM. Williams P.L. Gray's Anatomy: The anatomical basis of medicine \& surgery. $38^{\text {th }}$ ed. Churchill Livingstone; 1995.

[3] Frazier PD. Adult human enamel: an electron microscopic study of crystallite size and morphology. J Ultrastruct Res 1986; 22: 1-11.

[4] Habelitz S, Marshall SJ, Marshall GW, Balooch M. Mechanical properties of human dental enamel on the nanometre scale. Arch Oral Biol 2001; 46: 173-83.

[5] Daculsi G, Menanteau J, Kerebel LM, Mitre D. Length and shape of enamel crystals. Calcif Tissue Int 1984; 36: 550-5.

[6] Nanci A. Ten cates's oral histology: development, structure and function. $7^{\text {th }}$ ed. St Louis: Mosby; 2003.

[7] Maas MC, Dumont ER. Built to last: the structure, function and evolution of primate dental enamel. Evol Anthropol 1999; 8: 133-52.

[8] Imbeni V, Kruzic JJ, Marshall GW, Marshall SJ, Ritchie RO. The dentin-enamel junction and the fracture of human teeth. Nat Mater 2005; 4: 229-32.

[9] Koester KJ, Ager JW, Ritchie RO. The effect of aging on crack-growth resistance and toughening mechanisms in human dentin. Biomaterials 2008; 29; 1318-28.

[10] Kruzic JJ, Nalla RK, Kinney JH, Ritchie RO. Crack blunting, crack bridging and resistance-curve fracture mechanics in dentin: effect of hydration. Biomaterials 2003; 24; 5209-21.

[11] Nalla RK, Kinney JH, Tomsia AP, Ritchie RO. Role of alcohol in the fracture resistance of teeth. J Dent Res 2006; 85; 1022-6.

[12] Nalla RK, Kruzic JJ, Ritchie RO. On the origin of the toughness of mineralized tissue: microcracking or crack-bridging? Bone 2004; 34: 790-8.

[13] Nalla RK, Kinney JH, Ritchie RO. Effect of orientation on the in vitro fracture toughness of dentin: the role of toughening mechanisms. Biomaterials 2003; 24: 3955-68. 
[14] Mowafy OM, Watts DC. Fracture toughness of human dentin. J Dent Res 1986; 65: 67781.

[15] White SN, Luo W, Paine ML, Fong H, Sarikaya M, Snead ML. Biological organization of hydroxyapatite crystallites into a fibrous continumm toughens and controls anisotropy in human enamel. J Dent Res: 2001; 80: 321-6.

[16] Hassan R, Caputo AA, Bunshah RF. Fracture toughness of human enamel. J Dent Res 1981; 60: 820-7.

[17] Xu HHK, Smith DT, Jahanmir S, Romberg E, Kelly JR, Thompson VP, Rekow ED. Indentation damage and mechanical properties of human enamel and dentin. J Dent Res 1998; 77: 472-80.

[18] Park S, Quinn JB, Romberg E, Arola D. On the brittleness of enamel and selected dental materials. Dent Mater 2008; 24:1477-85.

[19] Anstis GR, Chantikul P, Lawn BR, Marshall DB. A critical evaluation of indentation techniques for measuring fracture toughness: I, direct crack measurements. J Am Ceram Soc 1981; 64: 533-8.

[20] Lawn B. Fracture of brittle solids. $2^{\text {nd }}$ ed. Cambridge: Cambridge University Press; 1993. [21] Quinn DQ, Bradt RC. On the Vickers indentation fracture toughness test. J Am Ceram Soc 2007; 90: 673-80.

[22] Bajaj D, Arola DD. On the R-curve behaviour of human tooth enamel. Biomaterials 2009; 30: 4037-46.

[23] Jelitto H, Felten F, Swain MV, Balke H, Schneider GA. Measurement of the total energy release rate for cracks in PZT under combined mechanical and electrical load. J Appl Mech 2007; 74: 1197-211.

[24] Munz D, Fett T, Ceramics - Mechanical properties, failure behaviour and materials selection. $2^{\text {nd }}$ ed. New York: Springer; 2001.

[25] Kounga Njiwa AB, Fett T, Lupascu DC, Rödel J. Effect of geometry and electrical boundary conditions on R-curve for lead zirconate titanate ceramics. Eng Fract Mech 2006; 73: 309-17.

[26] Oesterle LJ, Shellhart WC, Belanger GK. The use of bovine enamel in bonding studies. Am J Orthod Dentofac Orthop 1998; 114: 514-20.

[27] Sanches RP, Otani C, Damiao AJ, Miyakawa W. AFM characterization of bovine enamel and dentine after acid etching. Micron 2009; 40: 502-6.

[28] Habelitz S, Marshall GW, Balooch M, Marshall SJ. Nanoindentation and storage of teeth. J Biomec 2002; 35: 995-8.

[29] Bargel HJ, Schulze G. Werkstoffkunde. $7^{\text {th }}$ ed. Springer; 2000.

[30] Chai H, Lee JJW, Constantino PJ, Lucas PW, Lawn BR. Remarkable resilience of teeth. Proc Natl Acad Sci 2009, 106: 7289-93.

[31] Lin C, Douglas WH. Structure-property relations and crack resistance at the bovine dentin-enamel junction. J Dent Res 1994; 73: 1072-8.

[32] Tesch W, Eidelmann N, Roschger P, Goldenberg F, Klaushofer K, Fratzl P. Graded microstructure and mechanical properties of human crown dentin. Calcif Tissue Int 2001; 69: $147-57$.

[33] Lee JJW, Kwon JY, Chai H, Lucas PW, Thompson VP, Lawn BR. Fracture modes in human teeth. J Dent Res 2009; 88: 224-8.

[34] Nanci A. Ten Cate's oral histology. $7^{\text {th }}$ ed. St Louis, Missouri: Mosby; 2008. 


\section{A.1 Appendix}

\section{Computation of a mixed-mode stress intensity for oblique crack propagation with initial straight notch}

Stress intensity factor handbooks like [A1] commonly provide two geometry function solutions for oblique propagating cracks in samples loaded to pure bending (i.e. 4-point bending):

The solution for a 'kink crack' (figure A1a) with infinitely small kink at the tip of an initial straight crack of length a and the solution for a 'slant crack' (figure A1b) with crack and notch lying on the same linear slope.
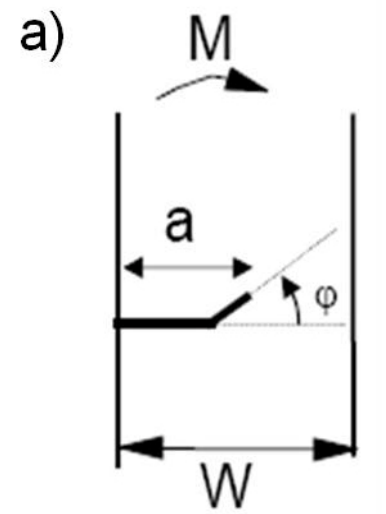

b)

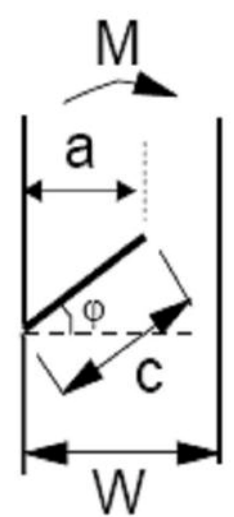

Figure A1: geometry of a) kink crack and b) slant crack

Due to oblique crack propagation, mixed-mode stress intensity conditions are induced at the crack tip. The according formulas of the geometric functions $F_{I \text { slant, kink }}$ and $F_{I I}$ slant, kink for calculating the stress intensity factors $\mathrm{K}_{\mathrm{I}}$ (tensile loading) and $\mathrm{K}_{\mathrm{II}}$ (in-plane shear) that are acting simultaneously at the crack tip are:

$$
\begin{aligned}
& F_{I, \text { kink }}=F_{I, \text { bend }} \cos ^{3}(\varphi / 2) \\
& F_{I I, \text { kink }}=F_{I, \text { bend }} \sin (\varphi / 2) \cos ^{2}(\varphi / 2)
\end{aligned}
$$

with $\mathrm{F}_{\mathrm{I} \text {,bend }}$ being the standard geometry function for an edge-cracked bar in pure bending (see [A1]) and

$$
\begin{aligned}
& F_{I, \text { slant }}\left(\varphi=45^{\circ}\right)=\frac{0,39+0,453 \exp (-4,21 \alpha)}{(1-\alpha)^{3 / 2}} \\
& F_{I I, \text { slant }}\left(\varphi=45^{\circ}\right)=\frac{1 / 9+0,3246 \exp (-3,542 \alpha)}{(1-\alpha)^{3 / 2}}
\end{aligned}
$$

with $\alpha=\mathrm{a} / \mathrm{W}$ where $\mathrm{a}$ is the crack length as indicated in figure A1b and $\mathrm{W}$ is the sample width. Only formulas for $\varphi=45^{\circ}$ are presented here, as this was the relevant angle for the current study.

An estimation of $F_{I}$ and $F_{I I}$ for the oblique crack with straight notch (geometry see figure A2) from the limit values $c_{2} / a=0$ (infinitely small kink at the tip of a straight crack) and $c_{2} / a=1$ (slant crack in bending) derived before is possible by interpolation according to 


$$
F_{I, I I-4 P B}=F_{I, I I, \text { kink }}+\left(F_{I, I I, \text { slant }}-F_{I, I I, \text { kink }}\right) \tanh \left(\lambda_{I, I I} \frac{c_{2}}{a}\right)
$$

with $\lambda_{\mathrm{I}}=25$ and $\lambda_{\mathrm{II}}=12$.

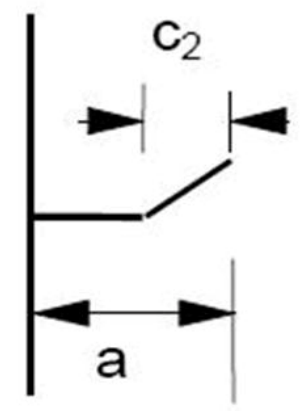

Figure A2: geometry of oblique crack with straight notch

If 3-point bending is applied, the geometric functions derived before for 4-point bending can be re-computed from

$$
\left(F_{I, I I, \text { kink }}, F_{I, I I, \text { slant }}\right)_{3-P B} \cong\left(F_{I, I I, \text { kink }}, F_{I, I I, \text { slant }}\right)_{4-P B} \frac{F_{I, \text { bend }-3 P B}}{F_{I, \text { bend }-4 P B}}
$$

where $\mathrm{F}_{\mathrm{I}, \text { bend-3PB }}$ and $\mathrm{F}_{\mathrm{I}, \text { bend-4PB }}$ are the standard geometric functions for SENB samples in 3point and 4-point bending, respectively (formulas for various length-to-height ratios L/W can be found in $[\mathrm{A} 1, \mathrm{~A} 2]$ ). For a typical value of $2 \mathrm{~L} / \mathrm{W}=0,15$ (the ratio used in this study) the ratio $\mathrm{F}_{\mathrm{I} \text {,bend-3PB }} / \mathrm{F}_{\mathrm{I}, \text { bend-4PB }}$ can be approximated by

$\frac{F_{I, \text { bend }-3 P B}}{F_{I, b e n d-4 P B}} \cong 0,95+0,05 \frac{a}{W}$

as shown in figure A3. 


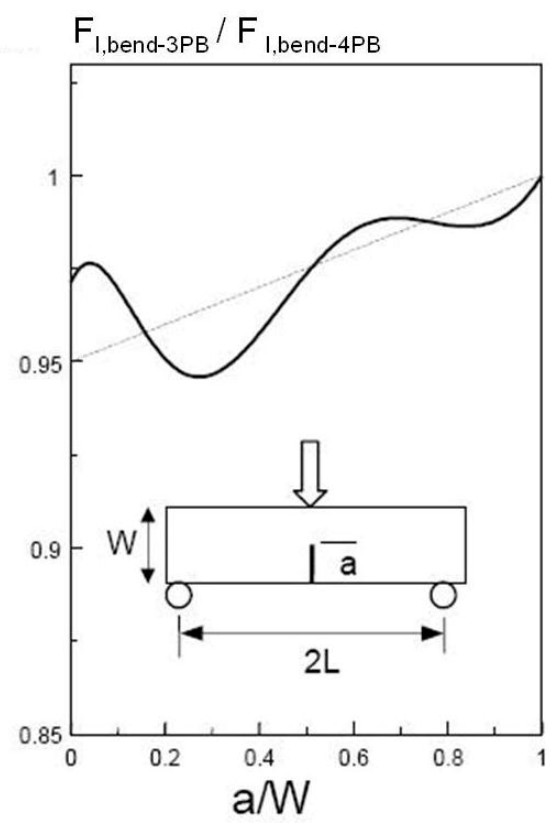

Figure A3: Differences in stress intensity factors for 3-point and 4-point bending. The dash-dotted line shows the approximation according to formula A6.

This leads to the following formulas $\mathrm{F}_{\mathrm{I}}$ and $\mathrm{F}_{\mathrm{II}}$

$F_{I, I I}=F_{I, I I-4 P B} \cdot \frac{F_{I, \text { bend }-3 P B}}{F_{I, \text { bend }-4 P B}}$

that can be used to calculate the mixed-mode stress intensity factors $K_{I}$ and $K_{I I}$ for oblique crack propagation with straight notch loaded in 3-point bending due to

$K_{I, I I}=\sigma \sqrt{\pi a} \cdot F_{I, I I}$

where $\sigma$ is the bending stress and a is the crack length as indicated in figure A2.

[A1] Fett T. Stress intensity factors, T-stresses, weight functions. Universitätsverlag Karlsruhe; 2008.

[A2] Munz D, Fett T. Ceramics - mechanical properties, failure behaviour and materials selection. Springer; 2001. 